(2) Open Access Full Text Article

\title{
Ignoring the sacroiliac joint in chronic low back pain is costly
}

This article was published in the following Dove Press journal:

ClinicoEconomics and Outcomes Research

21 January 2016

Number of times this article has been viewed

\section{David W Polly ${ }^{1,2}$ \\ Daniel Cher ${ }^{3}$}

'Department of Orthopedic Surgery, ${ }^{2}$ Department of Neurosurgery, University of Minnesota, Minneapolis, $\mathrm{MN},{ }^{3} \mathrm{SI}-\mathrm{BONE}$, Inc., San Jose, CA, USA

Correspondence: Daniel Cher SI-BONE, Inc., 3055 Olin Avenue, Suite 2200, San Jose, CA 95128 , USA Tel +l 6502695763

Email dcher@si-bone.com
Background: Increasing evidence supports minimally invasive sacroiliac joint (SIJ) fusion as a safe and effective treatment for SIJ dysfunction. Failure to include the SIJ in the diagnostic evaluation of low back pain could result in unnecessary health care expenses.

Design: Decision analytic cost model.

Methods: A decision analytic model calculating 2-year direct health care costs in patients with chronic low back pain considering lumbar fusion surgery was used.

Results: The strategy of including the SIJ in the preoperative diagnostic workup of chronic low back pain saves an expected US\$3,100 per patient over 2 years. Cost savings were robust to reasonable ranges for costs and probabilities, such as the probability of diagnosis and the probability of successful surgical treatment.

Conclusion: Including the SIJ as part of the diagnostic strategy in preoperative patients with chronic low back pain is likely to be cost saving in the short term.

Keywords: chronic low back pain, lumbar fusion, sacroiliac joint pain, sacroiliac joint fusion, healthcare costs, decision modeling

\section{Background}

Chronic back pain continues to be an important health epidemic. In its recent report, the World Health Organization included medications for chronic pain on its priority list of conditions. ${ }^{1}$ Chronic back pain is a common cause of loss of disability-adjusted life years globally. ${ }^{2}$

Degeneration of the lumbar spine is a common finding, and lumbar fusion (LF) has become an increasingly used surgery to treat chronic low back pain associated with various causes. The rate of LF has risen 2.4-fold in the decade between 1998 and 2008 , and the cost per case has more than tripled during this period. ${ }^{3}$ Despite this increase in use, success rates from LF continue to be low, and failed back surgery syndrome (FBSS), a term for continued pain after spine surgery, has become an important clinical entity. ${ }^{4}$ The economic impact of inadequate response to LF and failed back surgery syndrome is large, with costs of $>$ \$US 100,000 per patient over 4 years. ${ }^{5,6}$ The notion that many spine surgeries are unnecessary is commonly cited in the lay press.

There has been increasing interest in the sacroiliac joint (SIJ) as an under-recognized cause of chronic low back pain. In patients presenting for evaluation of low back pain, the SIJ was determined to be the source of pain in $14 \%-22 \%$. $^{7,8}$ The SIJ is even more commonly (up to $40 \%{ }^{9,10}$ ) suspected as a source of low back pain in patients with prior LF. Currently available treatment options for SIJ dysfunction include physical therapy, ${ }^{11}$ SIJ steroid injections, ${ }^{12,13}$ radiofrequency ablation of the SIJ, ${ }^{14,15}$ and open ${ }^{16}$ or minimally 
invasive $^{17-22}$ SIJ fusion (SIJF). A recently published surgery vs nonsurgery randomized trial of SIJF using triangular titanium implants showed that the fusion group had marked postoperative improvements in SIJ pain, disability associated with SIJ pain, and quality of life; those randomized to nonsurgical care showed very few improvements. ${ }^{21}$

Many surgeons who care for patients with chronic low back pain do not look for SIJ dysfunction as a cause, possibly because, until recently, there was no adequate surgical treatment for the condition. These surgeons may instead offer LF for patients with no other obvious cause of pain, especially if magnetic resonance imaging (MRI) shows lumbar disc abnormalities. Although the number of reported studies of LF is large, well-controlled studies have shown that only approximately $60 \%$ of patients derive clinically important benefits from lumbar surgery. ${ }^{23}$ A systematic review ${ }^{24}$ of lumbar arthrodesis showed moderate improvements in pain and disability (as measured by Oswestry Disability Index ${ }^{25}$ ) after LF. Of the small number of available LF surgery vs nonsurgery randomized trials, very few have shown clinically important differences in response rates. High-quality evidence from surgery vs nonsurgery trials that supports the superiority of LF surgery remains sparse. ${ }^{26,27}$ Selection criteria for LF also continue to be somewhat controversial, especially given that MRI, which is used to confirm the presence of lumbar spine pathology, is often abnormal in healthy patients. ${ }^{28-30}$ Interestingly, in clinical trials to date, many patients with SIJ pain have a history of prior spinal fusion..$^{21,22}$ While it is possible that spinal fusion increases the risk for adjacent segment degeneration of the $\mathrm{SIJ}^{31}{ }^{31}$ it is also possible that SIJ pain is mistakenly diagnosed as lumbar spinal pain. The use of LF surgery in such cases would provide a reasonable explanation for the low observed success rates after spinal fusion, with attendant high costs of treating failures (which typically do not address SIJ pain). One recently published cohort of patients undergoing bilateral SIJF found that many patients had undergone prior LF. ${ }^{32}$ While the author suggested that his patients had both SIJ and lumbar spine pain, it is also possible that some of the patients' initial SIJ pain was misdiagnosed as lumbar pain.

It seems axiomatic that improved diagnosis should lead to a higher likelihood of appropriate treatment, with better outcomes and decreased costs. For back pain, the consideration of an important additional cause of pain, namely SIJ dysfunction, should therefore lead to improved health outcomes and decreased overall health care costs. To examine the impact of including the SIJ as part of the diagnostic workup for preoperative chronic low back pain, we constructed a decision analytic model using published information from clinical trials and cost information. The goal was to estimate potential third-party cost savings from inclusion of the SIJ as part of the diagnostic workup of preoperative chronic low back pain.

\section{Methods \\ Overview}

We created a decision analytic model that models 2-year direct health care costs for private US health insurers in the care of patients with unremitting chronic low back pain unresponsive to conservative care who are candidates for LF. We model two strategies: one in which the SIJ is considered as a potential cause of low back pain and one in which it is not.

\section{Model description}

The model used is described graphically in Figure 1. The model begins with a patient with chronic unremitting low back pain unresponsive to conservative treatment with abnormalities on lumbar spine MRI (eg, degenerative spondylolisthesis or lumbar disc degeneration) prompting the selection of LF as a surgical treatment strategy. In the upper strategy, the patient undergoes a diagnostic workup for SIJ dysfunction as a cause of pain. Workup involves specific physical examination testing followed by a confirmatory diagnostic SIJ block if physical exam points to the SIJ as a cause of pain. A series of physical examination tests have been used for decades to aid in the diagnosis of SIJ pain. Examples include compression test, flexion, abduction and external rotation (FABER) test, and Gaenslen's test. In a meta-analysis, having at least three positive physical examination signs was highly predictive of positive response to SIJ block. ${ }^{33}$ Diagnostic SIJ block involves the infiltration of local anesthetic into the SIJ under fluoroscopic guidance. A positive block is one that markedly and immediately decreases SIJ pain. Diagnostic SIJ block is recommended by numerous societies to aid in the diagnosis of SIJ dysfunction and is considered to be a confirmatory test for SIJ dysfunction. ${ }^{34-38}$ According to a systematic review and meta-analysis, a combination of three or more positive physical examination tests has $85 \%$ sensitivity, $76 \%$ specificity, and a diagnostic odds ratio of 17 in patients presenting with suspected SIJ pain. ${ }^{33}$ In our model, if the patient has a negative exam or positive exam followed by negative diagnostic SIJ block, the patient is not diagnosed with SIJ dysfunction and is assumed to undergo the originally planned LF. If the patient has physical examination findings and a positive confirmatory diagnostic SIJ block, the patient is assumed to have SIJ dysfunction and undergo minimally invasive SIJF 


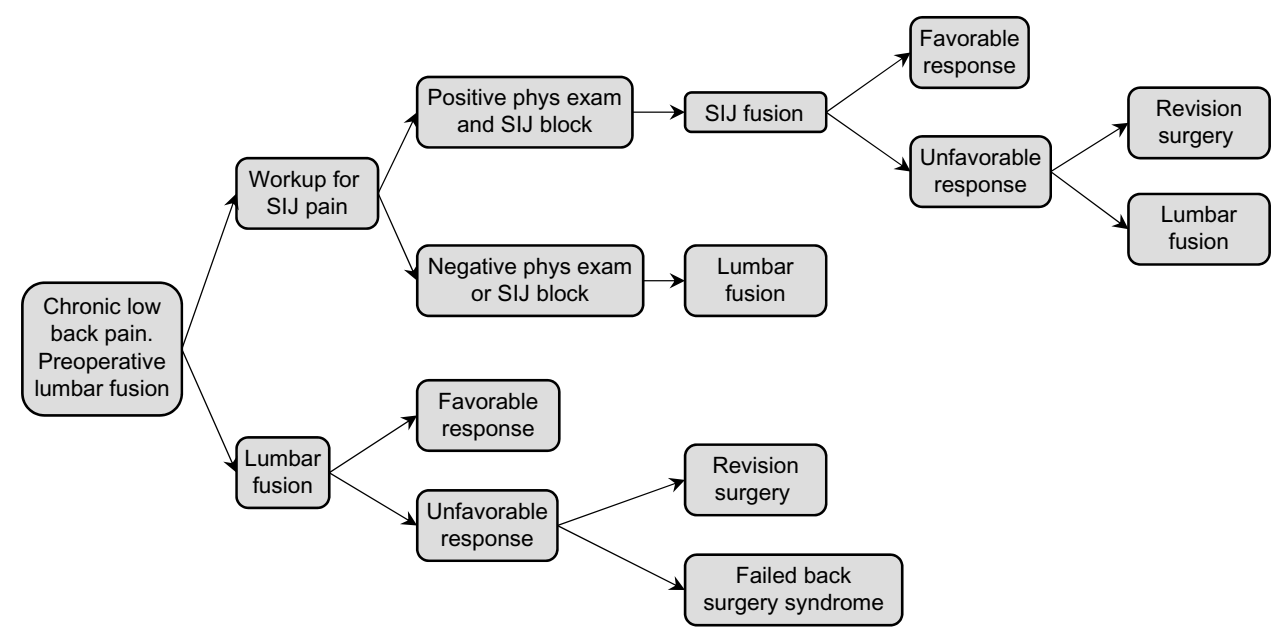

Figure I Graphical description of model used for calculations.

Abbreviations: SIJ, sacroiliac joint; phys exam, physical examination tests for SIJ pain.

using titanium implants, a surgery for which there is now substantial evidence of safety and effectiveness. ${ }^{21,22,39}$ If the patient has an unfavorable response to SIJF, we assumed he/she would immediately undergo follow-up LF, under the assumption that either SIJF failed to provide pain relief or the SIJ diagnosis was in error.

Patients who undergo LF (either immediately, ie, the lower strategy, or after workup with or without SIJF) also are assumed to have either favorable responses to the surgery or not. For both SIJF and LF, revision surgeries after each procedure can occur. Patients with unfavorable responses to LF who do not undergo or respond to revision surgery are assumed to have failed back surgery syndrome.

\section{Probability estimates}

Model probabilities and plausible ranges are based on assumptions shown in Table 1. Based on reports of prevalence rates in the outpatient setting, ${ }^{7,8} 15 \%-22 \%$ of patients have SIJ dysfunction as a cause of chronic low back pain. Although one SIJ block is commonly done, we conservatively modeled performance of two serial SIJ blocks to ensure confirmation of the SIJ diagnosis. Two prospective clinical trials have shown 6- and 12-month favorable response rates of $82 \%$, where response is defined as an improvement in self-rated SIJ pain of at least 20 points on the $0-100$ scale. $^{40,41}$ Outcomes from $4.5^{-20}$ to 5 -year ${ }^{42}$ cohorts, as summarized in a systematic review, ${ }^{39}$ substantiate high long-term response rates. Response rates after LF for degenerative spondylosis are lower; the most accurate estimates come from pre-market device trials, such as that for Infuse bone morphogenetic protein, which showed clinical success rates under $60 \%$. This value is consistent with the mean reduction in low back pain reported in a recently reported meta-analysis of relevant LF studies. ${ }^{24}$ Because LF for some indications (eg, degenerative spondylolisthesis) might have higher success rates, we explored a range of LF success rates. Revisions after SIJF occur at a rate of approximately $3.5 \%$ in 4 years. ${ }^{43}$ Repeat surgery after lumbar spine surgery occurs at a rate of approximately $8 \%$ in 4 years. ${ }^{44}$

\section{Cost estimates}

Cost estimates were taken from the US Centers for Medicare and Medicaid Services (CMS, also known as Medicare) payments to facilities and physicians depending on setting of care. Medicare payments are commonly used as a proxy for costs in cost-effectiveness analyses of spine interventions. ${ }^{45}$ Setting of care probabilities was based on CMS's physician and supplier public use file. All cost estimates were inflated $30 \%$ to represent the increased payments by commercial insurance reimbursements compared to CMS and are reported in US dollars. Payments for postoperative rehabilitation were not included. Revision surgeries were assumed to be $30 \%$ more expensive than both LF and SIJF index surgeries.

\section{Base-case analysis and sensitivity analysis}

The decision analytic model was programmed and analyzed using TreeAge Pro 2015. ${ }^{46}$ Incremental costs of pursuing the SIJ diagnostic strategy were determined. Multiple oneway sensitivity analyses using plausible ranges listed in Table 1 were conducted to test the robustness of the baseline results. Probabilistic sensitivity analysis was conducted using Monte Carlo simulation to allow all variables to vary simultaneously. For the probabilistic sensitivity analysis, key variables were assigned continuous distributions using 
Table I Probability and cost assumptions

\begin{tabular}{|c|c|c|c|c|}
\hline Description & Base case & Low & High & Source \\
\hline \multicolumn{5}{|l|}{ Probabilities } \\
\hline Positive SIJ block & 0.15 & 0.05 & 0.25 & Sembrano and Polly ${ }^{8}$ \\
\hline Successful response after SIJF & 0.82 & 0.7 & 0.85 & INSITE $^{21}$ and SIF| $\left.\right|^{22}$ \\
\hline Successful response after LF & 0.6 & 0.4 & 0.7 & Infuse summary of safety and effectiveness data ${ }^{23}$ \\
\hline Revision surgery in 4 years after SIJF & 0.035 & 0.03 & 0.08 & Cher et $\mathrm{a}^{43}$ \\
\hline $\begin{array}{l}\text { Successful response to LF after } \\
\text { negative SIJ block }\end{array}$ & 0.7 & 0.6 & 0.8 & $\begin{array}{l}\text { Expert opinion: If SIJ dysfunction ruled out as cause } \\
\text { of LBP, LF success rate might be higher }\end{array}$ \\
\hline $\begin{array}{l}\text { Probability of revision surgery after LF } \\
\text { in } 2 \text { years }\end{array}$ & 0.08 & 0.05 & 0.10 & Martin et $\mathrm{al}^{44}$ \\
\hline \multicolumn{5}{|l|}{ Costs in \$US } \\
\hline Physician/facility payment for SIJ block & 444 & 355 & 533 & $\begin{array}{l}\text { G0260 and CPT 27096, } 53 \% \text { office-based, } 47 \% \text { outpatient } \\
\text { facility-based }\end{array}$ \\
\hline SIJF & 13,636 & 10,000 & 18,000 & $\begin{array}{l}30 \% \text { inpatient, } 70 \% \text { outpatient } \\
\text { MS-DRG } 460 \text { and CPT } 27279 \\
\text { Ambulatory payment classification for SIJF }\end{array}$ \\
\hline Surgeon payment for SIJF & 574 & 459 & $689 *$ & CPT 27279 \\
\hline Anesthesia for SIJF & 180 & 144 & $216^{*}$ & CPT 01160,4 base units and 4 time units \\
\hline $\begin{array}{l}\text { Workup and treatment of poor } \\
\text { response to SIJF }\end{array}$ & 1,000 & 500 & 3,000 & $\begin{array}{l}\text { Expert opinion. Costs include additional physician visit, SIJ block, } \\
\text { and MRI }\end{array}$ \\
\hline LF & 22,339 & 20,000 & 30,000 & $\begin{array}{l}99 \% \text { inpatient, I\% outpatient } \\
\text { Facility payment: inpatient: MS-DRG } 460 \text { (US } \$ 21,596 \times 94 \%)+ \\
\text { MS-DRG } 459 \text { (US } \$ 36,006 \times 6 \%)=\text { US } \$ 22,461 \text {; outpatient: US } \$ 10,224\end{array}$ \\
\hline Surgeon payment for LF & 2,621 & 2,200 & 2,800 & $\begin{array}{l}\text { CPT 226I2, arthrodesis, posterior or posterolateral technique, single } \\
\text { level; lumbar (with lateral transverse technique when performed) } \\
\text { CPT 226I4, each additional vertebral segment }\end{array}$ \\
\hline Anesthesia for LF & 337 & 300 & 500 & I-hour anesthesia: 7 base units and 8 time units \\
\hline Failed back surgery syndrome over 2 years & 50,000 & 40,000 & 82,000 & Hollingworth et $\mathrm{al}^{5}$, Lad et $\mathrm{al}^{6}$ \\
\hline Revision surgery relative to index surgery & 1.3 & I.I & 1.5 & $\begin{array}{l}\text { Expert opinion: multiplier comparing cost of revision } \\
\text { surgery vs index surgery }\end{array}$ \\
\hline Cost multiplier Medicare & 1.3 & 1 & 1.6 & $\begin{array}{l}\text { Private health care insurance reimbursements exceed Medicare } \\
\text { payments by } 30 \%\end{array}$ \\
\hline
\end{tabular}

Note: *Range equal to $\pm 20 \%$.

Abbreviations: SIJ, sacroiliac joint; SIJF, SIJ fusion; INSITE, Investigation of Sacroiliac Fusion Treatment; SIFI, Sacroiliac Joint Fusion With iFuse Implant System ${ }^{\circledR}$; LBP, low back pain; LF, lumbar fusion; CPT, Current Procedural Terminology; MS-DRG, Medicare Severity-Diagnosis Related Group; MRI, magnetic resonance imaging.

uniform distributions, normal distributions, or beta distributions (for probability parameters), with variances corresponding to plausible minimum and maximum values. The $95 \%$ confidence interval for the distribution of incremental costs was determined.

\section{Results}

In the base case, the strategy of proceeding directly to LF had an expected 2-year cumulative cost of \$US 56,784. The strategy of including consideration of the SIJ had an expected 2 -year cost of $\$$ US 53,714. The cost savings over 2 years of the SIJ strategy was \$US 3,070 per patient. If a health plan performs 300 LFs annually, the 2-year cost savings of pursuing the SIJ workup strategy would be approximately \$US 869,000 . The likelihood of FBSS was decreased by $4 \%$ in the strategy that included SIJ consideration.

A multiway sensitivity analysis showed that the incremental cost saving of the SIJ strategy was sensitive to six important assumptions (probability of a positive SIJ block, probability of successful responses after SIJF or LF, costs of SIJF and LF, and costs of failed back surgery syndrome, Figure 2). To account for the effects of potential variation in success rates with LF given different underlying diagnoses (eg, a higher success rate with degenerative spondylolisthesis), a two-way sensitivity analysis (Figure 3) was performed. All modeled scenarios showed cost savings in the SIJ strategy except when the probability of a positive SIJ block was very low (5\%) and the postulated success rate for $\mathrm{LF}$ was higher than $68 \%$.

We also performed a probabilistic sensitivity analysis, focusing on the above six key variables that most impacted the cost model. With five tabled assumptions each for six distributions, there were 15,625 scenarios modeled. Of these scenarios, over 95\% showed lower costs in the SIJ workup strategy. This probabilistic analysis is consistent with a statistically significant cost saving for the SIJ strategy. To enable customized analysis with different assumptions that account for potential variation costs across health plans, 


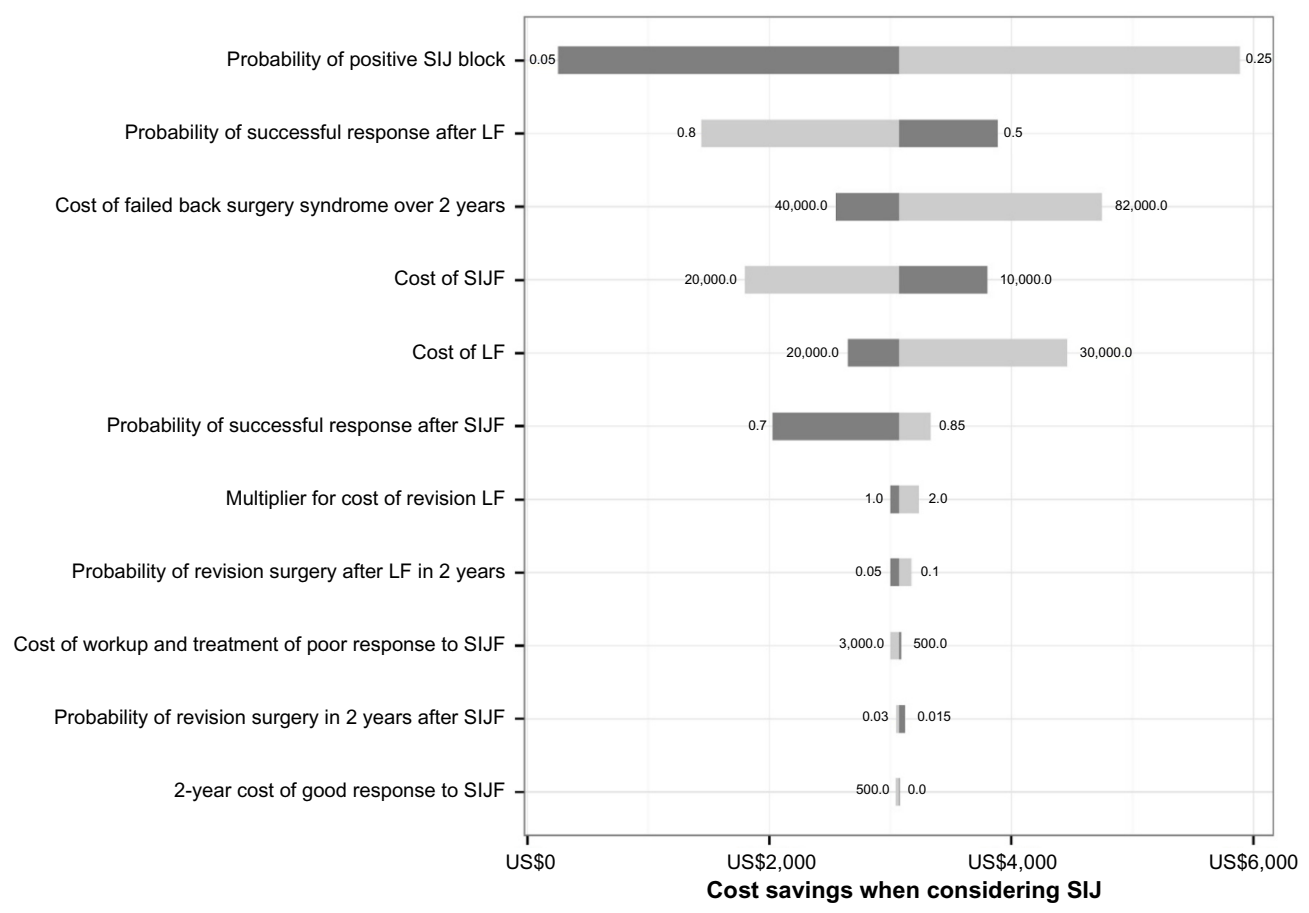

Figure 2 Tornado diagram for potential cost savings per patient associated with considering SIJ in workup of chronic low back pain for preoperative lumbar fusion patient. Notes: For each model parameter shown, the model was run using the lower and upper range of the plausible values. The plot shows the range of cost savings with the low/ high assumptions. When the higher estimate shows higher savings, it is shown with a light gray bar. When the lower estimate shows higher savings, it is shown with a dark gray bar. Parameters are ordered (top to bottom) by their effect on the cost savings range, which produces the "tornado" shape from which the diagram draws its name. Abbreviations: SIJ, sacroiliac joint; LF, lumbar fusion; SIJF, SIJ fusion.

output from probabilistic sensitivity analysis was exported, and a web page (http://siboneclinical.com/economic/model. html) was implemented to allow the user to choose from among a variety of assumptions regarding costs (Figure 4).

\section{Discussion}

Back pain is complex to diagnose and expensive to treat. The implications of chronic unremitting low back pain on health quality, worker productivity, and social dynamics are

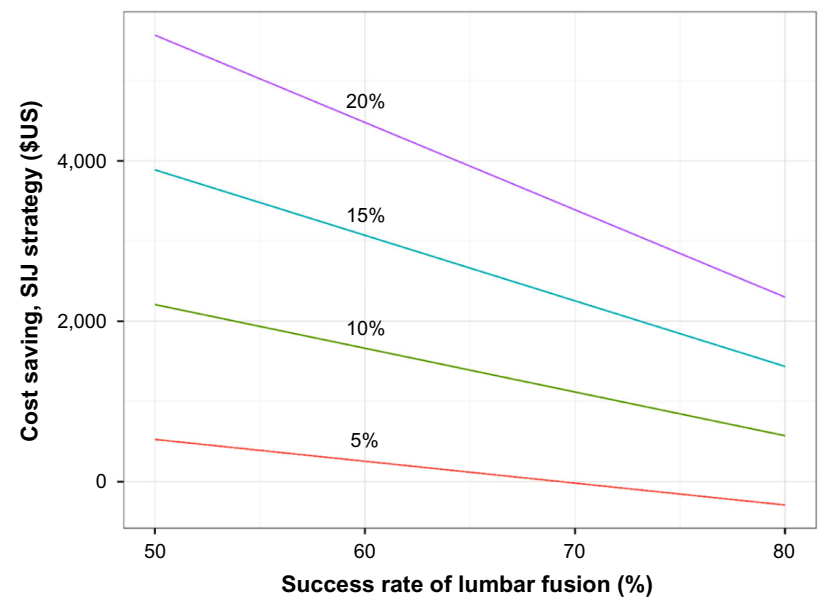

Figure 3 Two-way sensitivity analysis of cost savings as a function of lumbar fusion success rate (x-axis) and probability of a positive SIJ block (lines).

Abbreviation: SIJ, sacroiliac joint. marked. As with any area of medicine, inaccurate diagnosis leading to treatments that do not target the underlying disease exposes patients to risk without benefit. Poor outcomes after spine surgery are so common that practitioners in this area have created a unique term for this condition: failed back surgery syndrome. A PubMed search (July 7, 2015) showed 181 publications using this term in the article title.

SIJ dysfunction is a common cause of chronic low back pain and has been cited as contributing to back pain in $15 \%-22 \%$ of patients evaluated in the outpatient setting. ${ }^{7.8}$ The SIJ may be an even more common cause in patients who have already undergone LF. ${ }^{9} 10$ Possible explanations for the increased prevalence of SIJ pain in post-LF patients may include inaccurate diagnosis, adjacent segment degeneration, or concomitant pain generators. ${ }^{31}$ Regarding the former, a recently published analysis of a commercial payer population showed that $17 \%$ of patients who were diagnosed with SIJ dysfunction had undergone LF within the prior year. ${ }^{47}$ A similar analysis of the Medicare population showed that $7 \%$ had undergone lumbar spinal fusion surgery within 1 year before receiving a diagnosis of SIJ dysfunction. ${ }^{48}$ These figures suggest that misdiagnosis may be more common than previously reported. In one series of bilateral open SIJF, prior LF was very common. While the author suggested that SIJ and lumbar spine pain generators were both 


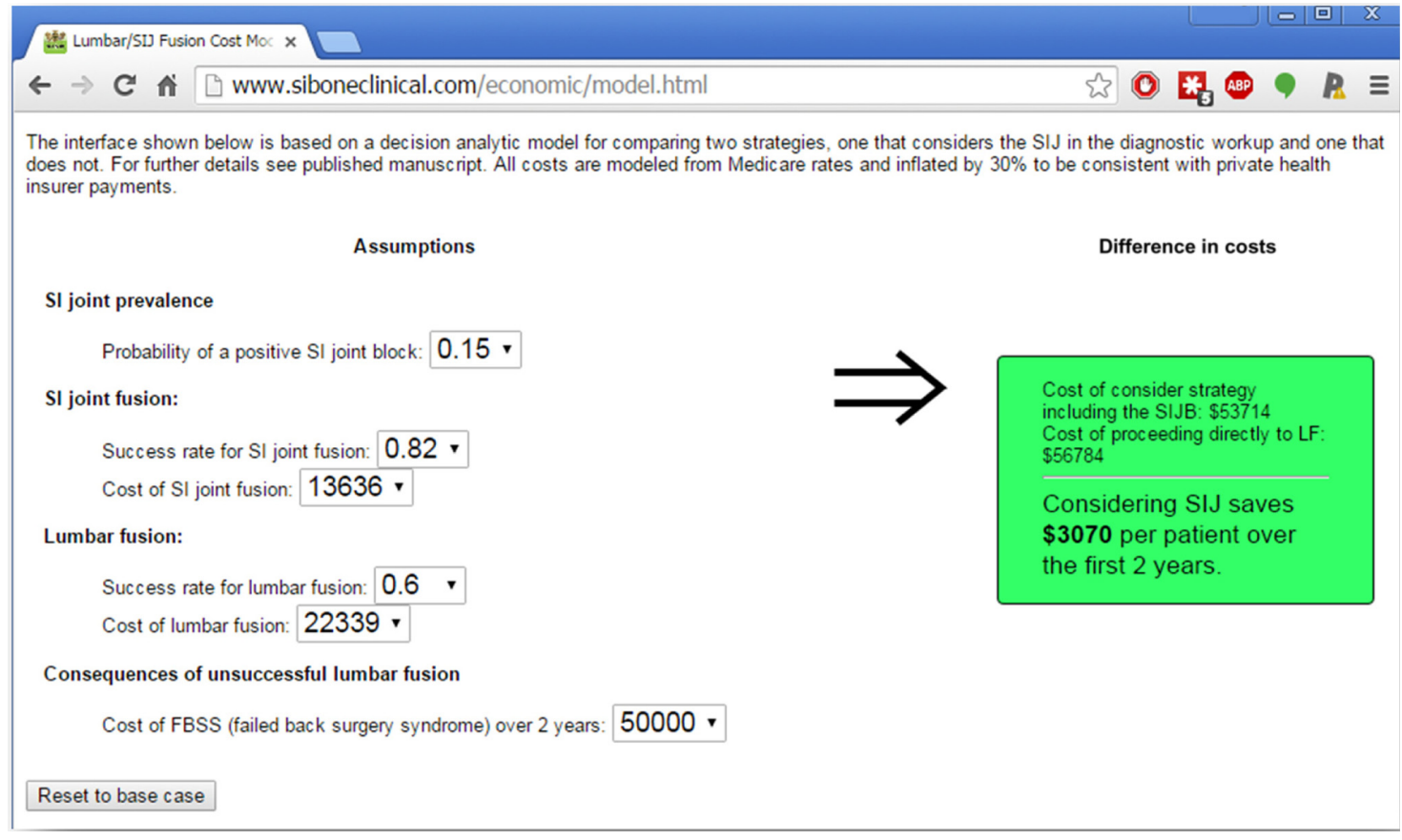

Figure 4 Screenshot of web interface for browsing probabilistic sensitivity analysis.

Note: Monetary values are shown in US dollars.

Abbreviations: FBSS, failed back surgery syndrome; SI, sacroiliac; SIJ, sacroiliac joint; SIJB, SIJ block.

present, a distinct possibility is that SIJ pain was initially misdiagnosed as being of lumbar spine origin. ${ }^{32}$

Including the SIJ during diagnostic workup of preoperative LF patients requires specific but relatively simple physical examination provocative maneuvers followed by a diagnostic SIJ block in patients with positive examination findings. Recommended by multiple physician societies as a reference standard, ${ }^{34-38}$ SIJ block is a brief, safe, and inexpensive procedure performed in the outpatient setting. Meta-analyses have shown that provocative physical examination tests have good predictive value for positive SIJ block. ${ }^{33}$ While desirable, radiographic markers of SIJ dysfunction are not currently available, and as in lumbar spine MRIs, ${ }^{28-30}$ imaging in the SIJ can often be positive in the absence of symptoms. ${ }^{49}$

A recent randomized trial of minimally invasive SIJF with triangular titanium implants vs nonsurgical management has shown that in patients with block-confirmed SIJ dysfunction due to degeneration or disruption of the SIJ, fusion results in improved pain, disability, and quality of life compared to nonsurgical treatment. ${ }^{21}$ A systematic review ${ }^{39}$ has shown sustained improvements in pain and disability to 5 years with this procedure. As the basis of our analysis, we believe that including the SIJ in the differential diagnosis and workup of patients with severe chronic low back pain considering surgery is beneficial in terms of both health outcomes and health expenditures. While a randomized trial of two diagnostic strategies we considered (ie, include the SIJ in the diagnostic workup vs not) is of interest, given the results of the randomized trial, ${ }^{21}$ surgeons who have included SIJF in their practice would likely refuse to participate, making such a trial impossible to execute. Thus, our goal in this manuscript was to use decision analytic techniques to estimate the potential magnitude of savings of this diagnostic strategy. The model used data from published clinical trials of LF and SIJF along with national (US) cost estimates for diagnosis and treatment, taking into account the high costs of failed lumbar spine surgery. The model calculated total direct 2-year health care costs of both strategies.

The strategy of including the SIJ in the diagnostic workup of chronic low back pain resulted in decreased total 2-year health care expenditures over a wide range of cost and probability assumptions. Cost estimates were sensitive to reasonable ranges in the model's most important assumptions; however, in both one-way analyses and probabilistic analyses, the strategy of including the SIJ as part of the diagnostic workup was nearly always cost saving. In the base case, the expected savings were approximately US $\$ 3,000$ per patient. Of note, these savings occurred over a short time frame (2 years) and are thus relevant to health plans with high patient turnover. Cost savings primarily resulted from high success rates in appropriately selected patients undergoing SIJF combined with a decreased 
expected number of patients with failed back surgery syndrome as a result of more careful diagnosis. The cost savings of this strategy far outweighed the additional cost associated with physical examination (essentially no cost) and diagnostic SIJ block (a low-cost, relatively risk-free procedure).

Our model may underestimate health care cost savings of including the SIJ in the diagnostic workup. The model made the strong assumption that a patient with chronic low back pain failing nonsurgical care who seeks surgery would be equally as desirous of undergoing SIJF or lumbar spine surgery. However, if diagnostic workup points to the SIJ as a cause of pain, it is possible that the patient and surgeon might decide to delay SIJF and opt for less costly nonsurgical treatments (SIJspecific physical therapy, SIJ steroid injections, etc), thereby reducing short-term costs. The model also assumed that patients not responding to SIJF would immediately undergo LF, but again, delay in having the latter surgery is possible, which would result in even further short-term cost savings.

Advantages of our model are the following: model assumptions were based on probability estimates derived from the published medical literature, including high-quality prospective clinical trials. Cost estimates were derived from federal government sources. The model's primary limitation is that some assumptions were based on information collected in different settings, and may not be applicable. Moreover, many assumptions regarding outcomes of SIJF were based on clinical trials sponsored by the device manufacturer. However, over a large range of assumptions, the model suggested cost savings for the strategy that includes SIJ consideration. In addition, most high-quality information regarding devices used during spine surgery derive from industry-sponsored clinical trials. ${ }^{50,51}$ Finally, the model did not include costs of postoperative rehabilitation. Given the increased invasiveness of LF compared to SIJF, postoperative rehabilitation for the former may be more intensive, so our model might be conservative in this regard.

\section{Conclusion}

In patients with unremitting chronic low back pain who are considering LF surgery, a diagnostic strategy that includes consideration of SIJ dysfunction could save approximately US $\$ 3,000$ per patient in the short term by providing more accurate treatment and avoiding unnecessary LF surgery.

\section{Author contributions}

David Polly contributed to manuscript idea, drafting, and editing. Daniel Cher was involved in modeling, statistical analysis, drafting, editing, and website programming.
Both authors contributed toward data analysis, drafting and critically revising the paper, and agree to be accountable for all aspects of the work.

\section{Disclosure}

David Polly has no financial conflict. Daniel Cher is an SIBONE employee. SI-BONE sponsored the clinical trial from which data were used in the reported model. SI-BONE manufactures the implant used in the SIJF surgery studied. The authors report no other conflicts of interest in this work.

\section{References}

1. Kaplan W, Wirtz VJ, Mantel-Teeuwisse A, Stolk P, Duthey B, Laing R. Priority Medicines for Europe and the World Update Report, 2013. World Health Organisation; 2013. Available from: http://www.who.int/ medicines/areas/priority_medicines/MasterDocJune28_FINAL_Web. pdf. February 1, 2015

2. Salomon JA, Vos T, Hogan DR, et al. Common values in assessing health outcomes from disease and injury: disability weights measurement study for the Global Burden of Disease Study 2010. Lancet. 2012;380(9859):2129-2143.

3. Rajaee SS, Bae HW, Kanim LEA, Delamarter RB. Spinal fusion in the United States: analysis of trends from 1998 to 2008. Spine 2012;37(1):67-76

4. Shapiro CM. The failed back surgery syndrome: pitfalls surrounding evaluation and treatment. Phys Med Rehabil Clin North Am. 2014;25(2):319-340.

5. Hollingworth W, Turner JA, Welton NJ, Comstock BA, Deyo RA. Costs and cost-effectiveness of spinal cord stimulation (SCS) for failed back surgery syndrome: an observational study in a workers' compensation population. Spine. 2011;36(24):2076-2083.

6. Lad SP, Babu R, Bagley JH, et al. Utilization of spinal cord stimulation in patients with failed back surgery syndrome. Spine. 2014;39(12): E719-E727.

7. Bernard TN, Kirkaldy-Willis WH. Recognizing specific characteristics of nonspecific low back pain. Clin Orthop. 1987;(217): 266-280.

8. Sembrano JN, Polly DW. How often is low back pain not coming from the back? Spine. 2009;34(1):E27-E32.

9. Liliang P-C, Lu K, Liang C-L, Tsai Y-D, Wang K-W, Chen H-J. Sacroiliac joint pain after lumbar and lumbosacral fusion: findings using dual sacroiliac joint blocks. Pain Med Malden Mass. 2011;12(4): $565-570$.

10. DePalma MJ, Ketchum JM, Saullo TR. Etiology of chronic low back pain in patients having undergone lumbar fusion. Pain Med. 2011;12(5):732-739.

11. Jackson R, Porter K. The pelvis and sacroiliac joint: physical therapy patient management utilizing current evidence. In: Current Concepts of Orthopaedic Physical Therapy. 3rd ed; La Crosse, WI, USA: American Physical Therapy Association; 2006.

12. Luukkainen R, Nissilä M, Asikainen E, et al. Periarticular corticosteroid treatment of the sacroiliac joint in patients with seronegative spondylarthropathy. Clin Exp Rheumatol. 1999;17(1):88-90.

13. Luukkainen RK, Wennerstrand PV, Kautiainen HH, Sanila MT, Asikainen EL. Efficacy of periarticular corticosteroid treatment of the sacroiliac joint in non-spondylarthropathic patients with chronic low back pain in the region of the sacroiliac joint. Clin Exp Rheumatol. 2002;20(1):52-54.

14. Cohen SP, Hurley RW, Buckenmaier CC, Kurihara C, Morlando B, Dragovich A. Randomized placebo-controlled study evaluating lateral branch radiofrequency denervation for sacroiliac joint pain. Anesthesiology. 2008;109(2):279-288. 
15. Patel N, Gross A, Brown L, Gekht G. A randomized, placebo-controlled study to assess the efficacy of lateral branch neurotomy for chronic sacroiliac joint pain. Pain Med Malden Mass. 2012;13(3):383-398.

16. Buchowski JM, Kebaish KM, Sinkov V, Cohen DB, Sieber AN, Kostuik JP. Functional and radiographic outcome of sacroiliac arthrodesis for the disorders of the sacroiliac joint. Spine J. 2005;5(5):520-528; discussion 529.

17. Sachs D, Capobianco R, Cher D, et al. One-year outcomes after minimally invasive sacroiliac joint fusion with a series of triangular implants: a multicenter, patient-level analysis. Med Devices Auckl NZ. 2014;7:299-304.

18. Cummings J Jr, Capobianco RA. Minimally invasive sacroiliac joint fusion: one-year outcomes in 18 patients. Ann Surg Innov Res. 2013;7(1):12.

19. Gaetani P, Miotti D, Risso A, et al. Percutaneous arthrodesis of sacroiliac joint: a pilot study. J Neurosurg Sci. 2013;57(4):297-301.

20. Vanaclocha V, Verdu-Lopez F, Sanchez-Pardo M, Gonzalbes-Esterelles L. Minimally invasive sacroiliac joint arthrodesis: experience in a prospective series with 24 patients. J Spine. 2015;3:7.

21. Polly DW, Cher DJ, Wine KD, et al. Randomized controlled trial of minimally invasive sacroiliac joint fusion using triangular titanium implants vs nonsurgical management for sacroiliac joint dysfunction: 12-month outcomes. Neurosurgery. 2015;77(5):674-691.

22. Duhon B, Cher D, Wine K, Kovalsky D, Lockstadt H, on behalf of the SIFI Study Group. Triangular titanium implants for minimally invasive sacroiliac joint fusion: a prospective study. Glob Spine J. Epub 2015 Aug 11.

23. Summary of Safety and Effectiveness Data: The InFUSE ${ }^{\mathrm{TM}}$ Bone Graft/LT-CAGE TM Lumbar Tapered Fusion Device; 2002. http://www. accessdata.fda.gov/cdrh_docs/pdf/P000058b.pdf. Accessed February 2, 2015.

24. Noshchenko A, Hoffecker L, Lindley EM, Burger EL, Cain CMJ, Patel VV. Long term treatment effects of lumbar arthrodeses in degenerative disc disease: a systematic review with meta analysis. J Spinal Disord Tech. 2015;28(9):E493-E521.

25. Fairbank JC, Pynsent PB. The Oswestry Disability Index. Spine. 2000;25(22):2940-2952; discussion 2952.

26. Gibson JA, Waddell G. Surgery for degenerative lumbar spondylosis. In: Cochrane Database of Systematic Reviews. John Wiley \& Sons, Ltd; 2005. http://onlinelibrary.wiley.com/doi/10.1002/14651858.CD001352. pub3/abstract. Accessed June 29, 2015.

27. Bydon M, De la Garza-Ramos R, Macki M, Baker A, Gokaslan ZL, Bydon A. Lumbar fusion versus non-operative management for treatment of discogenic low back pain: a systematic review and meta-analysis of randomized controlled trials. J Spinal Disord Tech. 2014:27(5):297-304.

28. Boden SD, Davis DO, Dina TS, Patronas NJ, Wiesel SW. Abnormal magnetic-resonance scans of the lumbar spine in asymptomatic subjects. A prospective investigation. J Bone Joint Surg Am. 1990;72(3): 403-408.

29. Boden SD. The use of radiographic imaging studies in the evaluation of patients who have degenerative disorders of the lumbar spine. J Bone Joint Surg Am. 1996;78(1):114-124.

30. Jensen MC, Brant-Zawadzki MN, Obuchowski N, Modic MT, Malkasian D, Ross JS. Magnetic resonance imaging of the lumbar spine in people without back pain. N Engl J Med. 1994;331(2):69-73.

31. Ha K-Y, Lee J-S, Kim K-W. Degeneration of sacroiliac joint after instrumented lumbar or lumbosacral fusion: a prospective cohort study over five-year follow-up. Spine. 2008;33(11):1192-1198.

32. Dall BE, Eden SV. Outcomes of bilateral sacroiliac joint fusions and the importance of understanding potential coexisting lumbosacral pathology that might also require surgical treatment. Acta Orthop Belg. 2015;81(2):233-239.

33. Szadek KM, van der Wurff P, van Tulder MW, Zuurmond WW, Perez RSGM. Diagnostic validity of criteria for sacroiliac joint pain: a systematic review. J Pain. 2009;10(4):354-368.
34. Pauza KJ, Aprill C, Bogduk N, et al. Educational Guidelines for Interventional Spinal Procedures. Rosemont, IL, USA: American Academy of Physical Medicine and Rehabilitation; 2008:1-48. http://www.aapmr.org/ practice/guidelines/documents/edguidelines.pdf. Accessed February 1, 2015.

35. Manchikanti L, Abdi S, Atluri S, et al. An update of comprehensive evidence-based guidelines for interventional techniques in chronic spinal pain. Part II: guidance and recommendations. Pain Physician. 2013;16(2 Suppl):S49-S283.

36. Bogduk N. Sacroiliac joint access. In: Bogduk N, editor. Practice Guidelines for Spinal Diagnostic and Treatment Procedures. 2nd ed. San Francisco: International Spine Intervention Society; 2013:523-555.

37. American Society of Anesthesiologists Task Force on Chronic Pain Management, American Society of Regional Anesthesia and Pain Medicine. Practice guidelines for chronic pain management: an updated report by the American Society of Anesthesiologists Task Force on Chronic Pain Management and the American Society of Regional Anesthesia and Pain Medicine. Anesthesiology. 2010;112(4):810-833.

38. Merskey H, Bogduk N. Classification of chronic pain: descriptions of chronic pain syndromes and definitions of pain terms. 2nd ed. Seattle: IASP Press; 1994 [reprinted 2002].

39. Heiney J, Capobianco R, Cher D. Systematic review of minimally invasive sacroiliac joint fusion using a lateral transarticular approach. Int J Spine Surg. 2015;9:Article 40.

40. Duhon B, Cher D, Wine K, Lockstadt H, Kovalsky D, Soo C-L. Safety and 6-month effectiveness of minimally invasive sacroiliac joint fusion: a prospective study. Med Devices Evid Res. 2013;6:219-229.

41. Whang PG, Cher D, Polly D, et al. Sacroiliac joint fusion using triangular titanium implants vs non-surgical management: six-month outcomes from a prospective randomized controlled trial. Int J Spine Surg. 2015;9(6).

42. Rudolf L, Capobianco R. Five-year clinical and radiographic outcomes after minimally invasive sacroiliac joint fusion using triangular implants. Open Orthop J. 2014;8:375-383.

43. Cher D, Reckling WC, Capobianco R. Implant survivorship analysis after minimally invasive sacroiliac joint fusion using the iFuse Implant System ${ }^{\circledR}$. Med Devices Evid Res. 2015:485-492

44. Martin BI, Mirza SK, Comstock BA, Gray DT, Kreuter W, Deyo RA. Reoperation rates following lumbar spine surgery and the influence of spinal fusion procedures. Spine. 2007;32(3):382-387.

45. Alvin MD, Miller JA, Lubelski D, et al. Variations in cost calculations in spine surgery cost-effectiveness research. Neurosurg Focus. 2014;36(6):E1.

46. TreeAge Pro 2015, R1.0. Williamstown, MA: TreeAge Software. Available from: http://www.treeage.com. Accessed February 2, 2015.

47. Ackerman S, Polly DW, Holt T, Cummings JT, Knight T. Management of sacroiliac joint disruption and degenerative sacroiliitis with nonoperative care is medical resource-intensive and costly in a United States commercial payer population. Clin Outcomes Res. 2014;2014(6): 63-74.

48. Ackerman SJ, Polly DW Jr, Knight T, Holt T, Cummings J Jr. Nonoperative care to manage sacroiliac joint disruption and degenerative sacroiliitis: high costs and medical resource utilization in the United States Medicare population. J Neurosurg Spine. 2014;20(4): 354-363.

49. Eno J-J, Boone C, Bellino M, Bishop J. The prevalence of sacroiliac joint degeneration in asymptomatic adults. J Bone Joint Surg Am. 2015;97(11):932-936.

50. Cher D, Capobianco R. Spine device clinical trials: design and sponsorship. Spine J. 2015;15(3):1133-1140.

51. Cher D. Industry sponsorship of spine device trials is the norm. Neurosurgery. Epub 2015 Nov 19 


\section{Publish your work in this journal}

ClinicoEconomics \& Outcomes Research is an international, peerreviewed open-access journal focusing on Health Technology Assessment, Pharmacoeconomics and Outcomes Research in the areas of diagnosis, medical devices, and clinical, surgical and pharmacological intervention. The economic impact of health policy and health systems organization also constitute important areas of coverage. The manuscript management system is completely online and includes a very quick and fair peer-review system, which is all easy to use. Visit http://www.dovepress.com/testimonials.php to read real quotes from published authors.

Submit your manuscript here: http://www.dovepress.com/clinicoeconomics-and-outcomes-research-journal 